\title{
Decreased susceptibility to chlorhexidine and distribution of qacA/B genes among coagulase-negative Staphylococcus clinical samples
}

\author{
Bruna Costa Moura do Vale, Acácia Gentil Nogueira, Thiago André Cidral, Maria Carolina Soares Lopes and \\ Maria Celeste Nunes de Melo* (D)
}

\begin{abstract}
Background: Healthcare-associated infection (HAl) is a major public health problem. As a form of prevention and control, preparations of chlorhexidine are used extensively; however, the reduction of susceptibility to chlorhexidine has been reported. The aim of this study was to investigate the susceptibility to chlorhexidine and the distribution of the gacA/B genes in 211 clinical isolates of coagulase-negative Staphylococci (CoNS).

Methods: CoNS were identified by conventional biochemical tests. Antimicrobial susceptibility was tested by diskdiffusion. Minimum inhibitory concentration (MIC) of chlorhexidine was determined by agar dilution test; detection of the qacA/B and mecA genes were evaluated by PCR.

Results: The most frequently isolated species were S. epidermidis, S. hominis hominis, S. auricularis, and S. haemolyticus, respectively. The strains presented a multidrug resistance profile of $87 \%$, including methicillin resistance. Reduced susceptibility to chlorhexidine was observed in $31 \%$. The gacA/B genes were detected in samples resistant (32/32) and susceptible (17/32) to chlorhexidine. The vast majority (94\%) of the samples with reduced susceptibility to chlorhexidine were multidrug resistant.
\end{abstract}

Conclusions: Our results show that qacA/B genes are not restricted to strains expressing chlorhexidine resistance. Further studies are needed to understand how the expression of these genes occurs.

Keywords: Coagulase-negative Staphylococci, Chlorhexidine, Healthcare-associated infection, qacA/B genes

\section{Background}

Healthcare-associated infections (HAIs) have become a serious problem for global public health [1]. Coagulase -negative Staphylococci (CoNS) are among the main microorganisms involved in HAIs, particularly bloodstream infections and infections related to the use of invasive medical devices [2]. To prevent the occurrence of HAIs, control measures are required, such as the rational use of antibiotics and antiseptics. Chlorhexidine is the most commonly used antiseptic in healthcare settings in

\footnotetext{
* Correspondence: celmelo@gmail.com

Department of Microbiology and Parasitology, Medical Bacteriology Laboratory, Bioscience Center, Federal University of Rio Grande do Norte UFRN, Av. Senador Salgado Filho, S/N, Campus Universitário, Lagoa Nova, Natal, RN 59072-970, Brazil
}

infection control programs $[3,4]$ and is a cationic bisbiguanide used for different purposes such as in the decolonization of surfaces, in the treatment of puncture sites of central venous catheters, for washing patients in intensive care units, for the preoperative treatment of skin, and in hand hygiene [5]. Its mechanism of action involves damage in the outer cell wall layers and the cytoplasmic membrane causing the extravasation of intracellular constituents and consequently the destruction of the bacterium [6]. In recent years, there have been reports of the emergence of clinical isolates of Staphylococcus with reduced susceptibility to chlorhexidine, being mainly attributed the presence of the genes $q a c A$ and $q a c B$, which are located in plasmids and are very closely related. Therefore, the polymerase chain 
reaction (PCR) products are designated as $q a c A / B$ positive or negative [7]. Their functions consist of coding the proton-dependent efflux pump (QacA/QacB), a member of the major facilitator superfamily of transport proteins, organized into $14 \alpha$-helical transmembrane segments, capable of exporting chlorhexidine out of the bacteria. Some studies have suggested cross-resistance between the $q a c A / B$ genes and other antimicrobial agents, as the plasmids may carry multiple determinants of antimicrobial resistance, facilitating the maintenance of the strains in the hospital environment and their dissemination [8-10].

The presence of antiseptic resistance genes in clinical isolates of Staphylococcus aureus and CoNS is considered a novel issue in the practice of infection control. It is necessary to clarify some relevant points regarding the expression of this resistance, especially in CoNS $[11,12]$.

The objective of the present study was to investigate the frequency of isolates with reduced susceptibility to chlorhexidine and to evaluate the distribution of the $q a c A / B$ genes in clinical samples of coagulase-negative Staphylococci.

\section{Methods}

\section{Bacterial strains}

A total of 211 CoNS clinical isolates from six public and private hospitals in the city of Natal - RN, Brazil, collected from 2010 to 2015 were analysed in this study. The distribution of collection sites was as follows: 145 (69\%) blood, 31 (15\%) secretions, 21 (10\%) catheter tip, 7 (3\%) biological fluids, and 7 (3\%) clinical specimens classified as others. The isolates were identified at the species level through conventional biochemical tests [13].

\section{Antimicrobial susceptibility}

Antibiotic susceptibility testing was performed via the disk diffusion method in accordance with the Clinical and Laboratory Standards Institute (CLSI) Guidelines [14]. The antibiotics tested were penicillin G (Pen, $10 \mathrm{U}$ ), cefoxitin (Fox, $30 \mu \mathrm{g}$ ), linezolid (Lzd, $30 \mu \mathrm{g}$ ), erythromycin (Ery, $15 \mu \mathrm{g}$ ), gentamicin (Gen, $10 \mu \mathrm{g}$ ), clindamycin (Cli, $02 \mu \mathrm{g}$ ), tetracycline (Tet, $30 \mu \mathrm{g}$ ), ciprofloxacin (Cip, $05 \mu \mathrm{g}$ ), rifampicin (Rif, $05 \mu \mathrm{g}$ ), chloramphenicol (Chl, $30 \mu \mathrm{g}$ ), and sulfamethoxazole/trimethoprim (Sxt, $25 \mu \mathrm{g}$ ). A doubledisk diffusion test (D-test) was also performed to detect induced resistance to clindamycin. The antibiotic disks were purchased from Newprov (Paraná, Brazil). Vancomycin susceptibility was determined with the Etest according to the manufacturer's instructions (Liofilchem, Teramo, Italy). Oxacillin resistance was confirmed by detection of the mecA gene by standard PCR using primers and conditions previously described [15]. The isolates that showed resistance to three or more different classes of antimicrobials were considered multidrug resistant (MDR) [6].

\section{Minimum inhibitory concentration determination}

The determination of the Minimum Inhibitory Concentration (MIC) for chlorhexidine was performed using the agar dilution method [14]. The isolate was considered resistant to chlorhexidine when the $\mathrm{MIC}$ was $\geq 4 \mathrm{mg} / \mathrm{L}$ $[9,16,17]$. Seven different concentrations were tested by twofold dilution $(0.125-8 \mathrm{mg} / \mathrm{L})$, prepared from a stock solution of chlorhexidine of $800 \mathrm{mg} / \mathrm{L}$. Plates were incubated at $35^{\circ} \mathrm{C}$ and the reading was performed after $24 \mathrm{~h}$.

\section{Detection of the $q a c A / B$ genes}

To investigate the presence of the $q a c A / B$ genes, 32 samples with high MIC (4-8 mg/L) and 32 samples with MIC of $0,125-2 \mathrm{mg} / \mathrm{L}$ were randomly selected. The genomic DNA was extracted following the thermal lysis methodology as previously described [18]. Conventional PCR was performed to detect the $q a c A / B$ genes, with the following sets of primers: 59-GCAGAAAGTGCAGA GTTCG-39 and 59-CCAGTCCAATCATGCCTG-39 (pro duct size $361 \mathrm{bp}$ ) [19]. $5 \mu \mathrm{l}$ DNA (100 ng) was added into the PCR mixture containing $12.5 \mu \mathrm{l} 1 \mathrm{X}$ PCR Master Mix (dNTP, $\mathrm{MgCl} 2$, and Taq DNA polymerase; Promega, USA), $5.5 \mu \mathrm{l}$ nuclease-free water, and $1 \mu \mathrm{l}(0.4 \mathrm{mM})$ of each primer. The PCR conditions used for detection of genes qac $A / B$ were as follows: initial denaturation step of $96^{\circ} \mathrm{C}$ for $3 \mathrm{~min}, 25 \mathrm{cycles}$ of $94^{\circ} \mathrm{C}$ for $20 \mathrm{~s}, 53^{\circ} \mathrm{C}$ for $20 \mathrm{~s}$, and 72 ${ }^{\circ} \mathrm{C}$ for $20 \mathrm{~s}$, and a final extension step at $72{ }^{\circ} \mathrm{C}$ for $5 \mathrm{~min}$. PCR products were analyzed by agarose gel electrophoresis. S. aureus 7644 strain was used as positive control and nuclease-free water as negative control.

\section{Results}

\section{Bacterial strains}

A total of 211 clinical samples of coagulase-negative Staphylococci were analyzed. It was possible to identify 14 different species of coagulase-negative Staphylococci, where the most frequently isolated species were $S$. epidermidis, S. hominis hominis, $S$ auricularis, and S. haemolyticus, respectively. Twenty-eight samples had inconclusive identification and were, therefore, classified only as coagulase-negative Staphylococcus (Table 1).

\section{Antimicrobial susceptibility}

Antibiotic susceptibility testing to the 12 previously mentioned antibiotics revealed that 184/211 (87\%) isolates were multidrug resistant. Multidrug resistance was distributed among all species (Table 1). Using the cefoxitin disk, $68.7 \%$ of the samples presented resistance, but after detecting the mecA gene by PCR, this occurrence increased to $80,5 \%$. Therefore, to $11.3 \%$ of the strains, the cefoxitin disk was not as sensitive for detection of 
Table 1 Multidrug resistance, resistance to chlorhexidine and resistance to methicillin from 211 clinical isolates of CoNS by species

\begin{tabular}{|c|c|c|c|c|}
\hline Species & $\mathrm{n}(\%)$ & MDR n (\%) & $\mathrm{MIC}$ of $\mathrm{CHX} \geq 4 \mathrm{mg} / \mathrm{L} \mathrm{n}(\%)$ & MIC of $\mathrm{CHX} \geq 4 \mathrm{mg} / \mathrm{L}$ and $\mathrm{MR} n(\%)$ \\
\hline S. epidermidis & $65(31)$ & $54(83)$ & $25(38.4)$ & $22(33,8)$ \\
\hline S. hominis hominis & $32(15.1)$ & $26(81)$ & $10(31.2)$ & $10(31,2)$ \\
\hline S. auricularis & $25(12)$ & $24(96)$ & $13(52)$ & $11(44)$ \\
\hline S. haemolyticus & $24(11.3)$ & $21(87.5)$ & $8(33.3)$ & $8(33,3)$ \\
\hline S. capitis urealyticus & $11(5.2)$ & $10(91)$ & $4(36.3)$ & $4(36,3)$ \\
\hline S. saccharolyticus & $5(2.3)$ & $4(80)$ & $1(20)$ & $1(20)$ \\
\hline S. chonii urealyticum & $5(2.3)$ & $5(100)$ & 0 & 0 \\
\hline S. cohnii cohnii & $4(1.8)$ & $4(100)$ & 0 & 0 \\
\hline S. saprophyticus & $4(1.8)$ & $4(100)$ & $1(25)$ & $1(25)$ \\
\hline S. capitis capitis & $3(1.4)$ & $3(100)$ & $1(33.3)$ & $1(33,3)$ \\
\hline S. chromogenes & $2(1.4)$ & $2(100)$ & 0 & 0 \\
\hline S. xylosus & $1(0.4)$ & $1(100)$ & 0 & 0 \\
\hline S. simulans & $1(0.4)$ & $1(100)$ & 0 & 0 \\
\hline S. sciuri & $1(0.4)$ & $1(100)$ & 0 & 0 \\
\hline Unidentified CoNS & $28(13.2)$ & $24(85.7)$ & $2(7.1)$ & $2(7,1)$ \\
\hline Total & $211(100)$ & $184(87)$ & $65(31)$ & $60(28,4)$ \\
\hline
\end{tabular}

MRD multidrug resistance, MIC minimum inhibitory concentration, $\mathrm{CHX}$ chlorhexidine, CoNS Coagulase-negative staphylococci, MR Methicillin-resistant

oxacillin resistance. Five strains were D-test positive. All samples were sensitive to vancomycin, exhibiting an $\mathrm{MIC} \leq 4 \mu \mathrm{g} / \mathrm{mL}[14]$.

\section{Minimum inhibitory concentration determination}

A total of $65 / 211$ (31\%) samples demonstrated reduced susceptibility to chlorhexidine, with MIC values ranging from $4 \mathrm{mg} / \mathrm{L}$ to $8 \mathrm{mg} / \mathrm{L}$. Reduced susceptibility to chlorhexidine was observed in several species (Table 1). The vast majority of strains resistant to chlorhexidine also showed multidrug resistance (94\%) and cefoxitin resistance (92\%).

\section{Detection of the qacA/B gene}

The $q a c A / B$ gene was searched in 64 samples, with 32 resistant to chlorhexidine and 32 susceptibles. All resistant samples were positive for the $q a c A / B$ gene. On the other hand, this gene was detected in 17 strains susceptible to chlorhexidine. The strains positive for the qacA/ $B$ gene presented a multidrug resistance profile $(82 \%)$ and cefoxitin resistance $(81 \%)$.

\section{Discussion}

In the present study, 211 clinical isolates of coagulasenegative Staphylococcus were investigated for susceptibility to antibiotics, decreased phenotypic susceptibility to chlorhexidine, and the presence of $q a c A / B$ genes, determinants of resistance to chlorhexidine.

The conventional methodology was not adequate to identify all species. This can be explained due to the great diversity of species of CoNS and their variable phenotypic characteristics. Staphylococcus epidermidis was most frequently isolated in this study, which agrees with the findings of other studies $[20,21]$. S. auricularis had a high occurrence, in contrast to other studies [20, $21]$, which reported a low prevalence. The identification through biochemical methods is still not completely reliable; however, other methodologies such as genotypic methods also have limitations [22, 23].

We observed a difference in the results obtained through the disk diffusion methodology with cefoxitin and by detection of the $\operatorname{mec} A$ gene. The cefoxitin disk was less sensitive in detecting heterologous populations of oxacillin resistant CoNS; this was also observed in another study carried out in Brazil [24]. The use of the combination of cefoxitin and oxacillin disks may improve the sensitivity of detection of oxacillin resistance in CoNS [25]. This approach is especially useful in laboratories that do not have access to mecA PCR, which is the gold standard method for detecting methicillin resistance. Accurate detection of oxacillin resistance is essential because false negative results may bring harm to the patient regarding the drugs of choice in the treatment.

With respect to the evaluation of the susceptibility of chlorhexidine, we observed in the literature that the percentage varies greatly, depending on the region studied, as well as the detection of the $q a c A / B$ genes [26, 27]. Due to this variability of data and the poorly studied geographic distribution of these genes [3], it is important to monitor the resistance to antiseptics in our territory. Our study verified a number of strains with reduced 
susceptibility to chlorhexidine similar to that reported in Taiwan with MRSA samples [9]. The identification of CoNS strains is concern since the selective pressure allows these strains to persist in the hospital environment, not only causing infections but also possibly transferring their resistance genes to chlorhexidine to other bacterial pathogens, including $S$. aureus. These results should not be ignored, because may they threaten the effectiveness of prevention and control practices of HAI. Therefore, it is essential that long-term surveillance programs be realized and that the factors related to this event be investigated.

All samples tested with reduced susceptibility to chlorhexidine harbored the $q a c A / B$ gene. Although other studies have demonstrated a strong relationship between $q a c A / B$ and reduced susceptibility to chlorhexidine [6, 28 ], it was observed in this study that the distribution of the $q a c A / B$ genes is not limited to strains expressing resistance to chlorhexidine. The presence of the $q a c A / B$ genes does not guarantee gene expression, its expression is influenced by transcription regulators, level of exposure and previous contact with cationic agents [16, 29]. Although we had investigated only the $q a c A / B$ genes, others resistence genes are also associated to biocide reduced susceptibility in staphylococci, including smr, qacH, qacJ, qacG and norA. Chlorhexidine susceptible strains carrying the $q a c A / B$ gene may be resistant to other antiseptics, which have not been tested in this study. The correlation between the presence of $q a c A / B$ and elevated MICs is still not fully understood and it has been demonstrated that the carriage of more than one determinants of resistance concomitantly in an isolate can increase the MIC of chlorhexidine [27].

The study showed that there is antiseptic and antibiotic co-resistance in coagulase-negative staphylococci strains. This was demonstrated by the fact that almost all isolates with reduced susceptibility to chlorhexidine and also displaying multidrug resistance. Furthermore, we detected a high frequency of $q a c A / B$ positive strains with multidrug resistance, similar to that reported by other authors $[4$, 17]. Genetic linkage between $q a c$ genes and genes conferring resistance to erythromycin, trimethoprim, and aminoglycosides on the same Staphylococcal plasmids has been reported [3, 19]. Regarding this, it is believed that the spread of resistance genes to antibiotics may be caused by the selective pressure of frequent use of chlorhexidine [9, $30,31]$. Our results corroborate such studies demonstrating the presence of strains with high pathogenic potential because they are resistant to the two forms of control of HAIs, antiseptics/disinfectants and antibiotics.

\section{Conclusions}

In conclusion, in the present study, $31 \%$ of coagulase -negative Staphylococcus isolated from clinical samples demonstrated reduction in susceptibility to chlorhexidine. The detection of the $q a c A / B$ genes was not sufficient to measure the susceptibility to chlorhexidine. The presence of antibiotic and antiseptic co-resistance hinders the elimination of these bacteria from the hospital environment and facilitates the transmission of resistance genes to other bacteria. The investigation of other factors related to the expression of the $q a c A / B$ gene would help to better understand resistance to chlorhexidine and provide crucial information for the control of HAIs.

\section{Abbreviations \\ CLSI: Clinical and Laboratory Standards Institute; CoNS: Coagulase negative staphylococci; HAl: Healthcare-associated Infection; MDR: Multidrug resistant; MIC: Minimum inhibitory concentration; MR: Methicillin-resistant; MRSA: Methicillin-resistant Staphylococcus aureus; PCR: Polymerase chain reaction; QAC: Quaternary ammonium compounds}

\section{Acknowledgements \\ The authors thank all partners for contributing to the development this study and elaboration of this article, the laboratories that have supplied the samples for the study, and Dra Maria Helena S. Villas Boas of the National Institute of Health Quality Control (INCQS), Oswaldo Cruz Foundation (Fiocruz), Brazil, for S. aureus strain 7644. No funding body had any role in the study design, data collection and analysis, decision to publish, or preparation of the manuscript. \\ Funding \\ The study was funded by Research Support Foundation of Rio Grande do Norte (FAPERN), National Council of Scientific and Technological Development (CNPq), Coordination for the Improvement of Higher Education Personnel (CAPES), and Federal University of Rio Grande do Norte (UFRN). The funding bodies had no role in study design, collection, analysis, and interpretation of data or in writing the manuscript.}

\section{Availability of data and materials}

The datasets used and/or analyzed during the current study are available from the corresponding author on reasonable request.

\section{Authors' contributions}

BCMV and MCNM designed the study protocol; BCMV, AGN, TAC, and MCSL performed the experiments; BCMV and MCNM analyzed the data; BCMV drafted the manuscript; and MCNM critically revised the manuscript for intellectual content. All authors read and approved the final manuscript. MCNM is guarantor of the paper.

\section{Ethics approval and consent to participate}

The study was approved and the consent to participate was waived by the Research Ethics Committee of the University Hospital Onofre Lopes - CEP/ HUOL, Brazil, according to Protocol n³20/09, CAAE: 0045.0.294.000-11.

\section{Consent for publication}

Not applicable.

Competing interests

All authors declare that they have no competing interests.

\section{Publisher's Note}

Springer Nature remains neutral with regard to jurisdictional claims in published maps and institutional affiliations. 
Received: 29 January 2018 Accepted: 15 February 2019

Published online: 27 February 2019

\section{References}

1. Heggendornn LH, Gomes SW, Silva NA, et al. Epidemiological profile and antimicrobial susceptibility of microorganisms isolated from nosocomial infections. Rev Saúde e meio Ambiente. 2016:2:26-47.

2. Nanoukon C, Argemi X, Sogbo F, et al. Pathogenic features of clinically significant coagulase-negative staphylococci in hospital and community infections in Benin. Int J Med Microbiol. 2017;307(1):75-82.

3. Conceição $\mathrm{T}, \mathrm{Co} \mathrm{C}$, Lencastre $\mathrm{H}$, et al. Prevalence of biocide resistance determinants in Staphylococcus aureus isolates from three African countries. Antimicrob Agents Chemother. 2016:60(1):678-81.

4. Schlett CD, Millar EV, Crawford KB, et al. Prevalence of chlorhexidineresistant methicillin-resistant Staphylococcus aureus following prolonged exposure. Antimicrob Agents Chemother. 2014;58(8):4404-10.

5. Donskey CJ, Deshpande A. Effect of chlorhexidine bathing in preventing infections and reducing skin burden and environmental contamination: a review of the literature. Am J Infect Control. 2016;44:e17-21.

6. Prag G, Falk-Brynhildsen K, Jacobsson S, et al. Decreased susceptibility to chlorhexidine and prevalence of disinfectant resistance genes among clinical isolates of Staphylococcus epidermidis. APMIS. 2014;122:961-7.

7. Hijazi K, Mukhopadhya I, Abbott F, et al. Susceptibility to chlorhexidine amongst multidrug-resistant clinical isolates of Staphylococcus epidermidis from bloodstream infections. Int J Antimicrob Agents. 2016;48:86-90.

8. Costa SS, Viveiros M, Amaral $\mathrm{L}$, et al. Multidrug efflux pumps in Staphylococcus aureus: an update. Open Microbiol J. 2013;7(Suppl 1-M5): 59-71.

9. Sheng WH, Wang JT, Lauderdale TL, et al. Epidemiology and susceptibilities of methicillin-resistant Staphylococcus aureus in Taiwan: emphasis on chlorhexidine susceptibility. Diagn Microbiol Infect Dis. 2009;63:309-13.

10. Fiebelkorn KR, Crawford SA, McElmeel ML, et al. Practical disk diffusion method for detection of inducible clindamycin resistance in Staphylococcus aureus and coagulase-negative staphylococci. J Clin Microbiol. 2003;41(10): 4740-4

11. Miyazaki NH, Abreu AO, Marin VA, et al. The presence of qacA/B gene in Brazilian methicillin-resistant Staphylococcus aureus. Mem Inst Oswaldo Cruz. 2007;104(4):539-0.

12. Teixeira CF, Pereira TB, Miyazaki NH, et al. Widespread distribution of qacA/B gene among coagulase-negative Staphylococcus spp. in Rio de Janeiro, Brazil. J Hosp Infect. 2010;75(4):333-4.

13. Murray PR, Baron EJ, et al. Manual of clinical microbiology. 9th ed. Washington, DC: ASM Press; 2007

14. CLSI. Performance standards for antimicrobial susceptibility testing. In: Twenty-Third Informational Supplement M100-S23. Wayne, PA, USA: Clinical and Laboratory Standards Institute; 2013. p. 2013.

15. Oliveira DC, Lencastre H. Multiplex PCR strategy for rapid identification of structural types and variants of the mec element in methicillin-resistant Staphylococcus aureus. Antimicrob Agents Chemother. 2002;46(7):2155-61.

16. Horner C, Mawer D, Wilcox M. Reduced susceptibility to chlorhexidine in staphylococci: is it increasing and does it matter? J Antimicrob Chemother. 2012:67(11):2547-59.

17. Wang JT, Sheng WH, Wang $\mathrm{J}$, et al. Longitudinal analysis of chlorhexidine susceptibilities of nosocomial methicillin-resistant Staphylococcus aureus isolates at a teaching hospital in Taiwan. J Antimicrob Chemother. 2008;62: 514-7.

18. Pacheco $A B$, Guth $B E$, Soares $K C$, et al. Random amplification of polymorphic DNA reveals serotype-specific clonal clusters among enterotoxigenic Escherichia coli strains isolated from humans. J Clin Microbiol. 1997:35(6):1521-5.

19. Noguchi N, Suwa J, Sasatsu M, et al. Susceptibilities to antiseptic agents and distribution of antiseptic-resistance genes qacA/B and smr of methicillinresistant Staphylococcus aureus isolated in Asia during 1998 and 1999. Med Microbiol. 2005;54(Pt6):557-65

20. Kleeman KT, Bannerman TL, Kloos WE. Species distribution of coagulasenegative staphylococcal isolates at a community hospital and implications for selection of staphylococcal identification procedures. J Clin Microbiol. 1993;31(5):1318-21.

21. Tayyar IA, AL-Zoubi MS, Hussein E, et al. Prevalence and antimicrobial susceptibility pattern of coagulase-negative staphylococci (CoNS) isolated from clinical specimens in northern of Jordan. Iran J Microbiol. 2015;7(6): 294-301.

22. Edwards KJ, Kaufmann ME, Saunders NA. Rapid and accurate identification of coagulase-negative staphylococci by real-time PCR. J Clin Microbiol. 2001 30(9):3047-51.

23. Heikens E, Fleer A, Paauw A, et al. Comparison of genotypic and phenotypic methods for species-level identification of clinical isolates of coagulasenegative staphylococci. J Clin Microbiol. 2005;43(5):2286-90.

24. Frigatto EA, Machado AM, Pignatari $A C$, et al. Is the cefoxitin disk test reliable enough to detect oxacillin resistance in coagulase-negative staphylococci? J Clin Microbiol. 2005:43(4):2028-9.

25. Ferreira AM, Bonesso MF, Mondelli AL, et al. Oxacillin resistance and antimicrobial susceptibility profile of Staphylococcus saprophyticus and other staphylococci isolated from patients with urinary tract infection. Chemotherapy. 2012:58(6):482-91.

26. Wassenaar TM, Ussery D, Nielsen LN, Ingmer H. Review and phylogenetic analysis of qac genes that reduce susceptibility to quaternary ammonium compounds in Staphylococcus species. Eur J Microbiol Immunol. 2015;5:44-61.

27. Damavandi MS, Dehkordi MS, Dehghan A, et al. Detection of antiseptic resistance genes among staphylococcus aureus colonising nurses and coagulase-negative staphylococci isolated from clinical specimens at teaching hospitals in southwest of Iran. Jundishapur J Microbiol. 2017;10(1): e39285.

28. Zhang M, O'Donoqhue MM, Hiramatsu K, et al. Prevalence of antisepticresistance genes in Staphylococcus aureus and coagulase-negative staphylococci colonising nurses and the general population in Hong Kong. J Hosp Infect. 2011;78(2):113-7.

29. Grkovic S, Brown MH, Schumacher MA, et al. The staphylococcal qacR multidrug regulator binds a correctly spaced operator as a pair of dimers. J Bacteriol. 2001;183(24):7101-9.

30. Noguchi N, Nakaminami H, Nishijima S, et al. Antimicrobial agent of susceptibilities and antiseptic resistance gene distribution among methicillin-resistant Staphylococcus aureus isolates from patients with impetigo and staphylococcal scalded skin syndrome. J Clin Microbiol. 2006; 44:2119-25

31. Anthonisen IL, Sunde M, Steinum TM, et al. Organization of the antiseptic resistance gene qacA and Tn552-related b-lactamase genes in multidrugresistant Staphylococcus haemolyticus strains of animal and human origins. Antimicrob Agents Chemother. 2002;46:3606-12

\section{Ready to submit your research? Choose BMC and benefit from:}

- fast, convenient online submission

- thorough peer review by experienced researchers in your field

- rapid publication on acceptance

- support for research data, including large and complex data types

- gold Open Access which fosters wider collaboration and increased citations

- maximum visibility for your research: over $100 \mathrm{M}$ website views per year

At $\mathrm{BMC}$, research is always in progress.

Learn more biomedcentral.com/submission 